\title{
Erratum to: Residual Deformity Is the Most Common Reason for Revision Hip Arthroscopy: A Three-dimensional CT Study
}

\author{
James R. Ross MD, Christopher M. Larson MD, \\ Olusanjo Adeoye MD, Bryan T. Kelly MD, \\ Asheesh Bedi MD
}

Published online: 13 January 2015

(C) The Association of Bone and Joint Surgeons( 2015

\section{Erratum to: Clin Orthop Relat Res \\ DOI: $10.1007 / \mathrm{s} 11999-014-4069-9$}

In the published study, "Residual Deformity Is the Most Common Reason for Revision Hip Arthroscopy: A Threedimensional CT Study" a coauthor's name is spelled incorrectly. The author's name is Olusanjo Adeoye MD.

The authors regret this error.

The online version of the original article can be found under doi:10.1007/s11999-014-4069-9.

J. R. Ross, A. Bedi ( $\square)$

Department of Orthopaedic Surgery, University of Michigan, MedSport, 24 Frank Lloyd Wright Drive, Ann Arbor, MI 48106,

USA

e-mail: abedi@umich.edu; abedi@med.umich.edu

C. M. Larson

Minnesota Orthopedic Sports Medicine Institute at Twin Cities

Orthopedics, Edina, MN, USA

O. Adeoye

Spectrum Health, Grand Rapids, MI, USA

B. T. Kelly

Hospital for Special Surgery, New York, NY, USA 